\title{
REPRESENTAÇÕES CONCEITUAIS DE DOCENTES DO MERCOSUL ACERCA DA TRANSVERSALIDADE
}

\author{
Cátia Silene Carrazoni Lopes Viçosa ${ }^{1}$ \\ Vanderlei Folmer ${ }^{2}$ \\ Andréia Caroline Fernandes Salgueiro ${ }^{3}$
}

\begin{abstract}
RESUMO
Este estudo propõe-se a investigar as concepções de docentes brasileiros, argentinos e uruguaios acerca da transversalidade na educação básica. Trata-se de uma pesquisa qualitativa de caráter exploratório. Participaram 96 docentes de escolas públicas situadas nas regiões periféricas de cidades que fazem parte da tríplice fronteira Brasil, Argentina e Uruguai. Os dados foram coletados por questionários, tratados e categorizados por meio da Análise de Conteúdo. Os resultados originam quatro categorias associadas: i) contextualização; ii) aprendizagem significativa; iii) formação de sujeitos; e iv) interdisciplinaridade. Os temas com maior frequência são semelhantes nos países pesquisados e estão relacionados ao Meio Ambiente e à Saúde. Quanto aos subsídios da formação continuada para o trabalho focado na transversalidade, o Uruguai destaca-se em relação à Argentina e ao Brasil. Conclui-se que as representações sobre transversalidade versam sobre transformação dos conceitos, explicitação de valores e inclusão de procedimentos vinculados ao cotidiano do educando. Assim, infere-se ser incipiente a inserção da transversalidade nas práticas educativas e nas formações continuadas da área fronteiriça, visando a ampliar os significados elaborados na construção do conhecimento, superar paradigmas tradicionais de ensino e aproximar os segmentos educacionais destes países.
\end{abstract}

Palavras-chave: aprendizagem; contextualização; cotidiano escolar; formação continuada.

\section{CONCEPTUAL REPRESENTATIONS OF MERCOSUR TEACHERS ABOUT TRANSVERSALITY}

\section{ABSTRACT}

This study aims to investigate the conceptions of Brazilian, Argentine and Uruguayan teachers about the transversality in basic education. It is an exploratory qualitative research. 96 professors working in public schools located in the peripheral regions of cities that are part of the triple border Brazil, Argentina and Uruguay participated. Data were collected through questionnaires, treated and categorized through Content Analysis. The results give rise to four associated categories: i) contextualization; ii) meaningful learning; iii) training of subjects; and iv) interdisciplinarity. The themes most frequently are similar in the countries surveyed and are related to the Environment and Health. As for the subsidies provided by continuing education for work focused on transversality, Uruguay stands out in relation to Argentina and Brazil. It is concluded that the representations about transversality are about the transformation of concepts, the explanation of values and the inclusion of procedures linked to the student's daily life. Thus, it appears that the insertion of transversality in the educational practices and in the continuous training of the border area is incipient, aiming at expanding the meanings elaborated in the construction of knowledge, overcoming traditional teaching paradigms and bringing the educational segments of these countries closer. Keywords: learning; contextualization; school life; continuing education.

Recebido em: $11 / 9 / 2020$

Aceito em: $29 / 9 / 2020$

\footnotetext{
1 Autora correspondente. Universidade Federal do Pampa, Campus Uruguaiana. BR 472, Km 585, Uruguaiana/RS, Brasil. CEP: $97501-97$. http://lattes.cnpq.br/2756461468265473. https://orcid.org/0000-0002-6909-0839. catialopes00@hotmail.com

2 Universidade Federal do Pampa, Campus Uruguaiana. Uruguaiana/RS, Brasil. http://lattes.cnpq.br/8135232309980269. https://orcid. org/0000-0001-6940-9080.

3 Universidade Federal do Pampa, Campus Uruguaiana. Uruguaiana/RS, Brasil. http://lattes.cnpq.br/5529127283220286. https://orcid. org/0000-0003-4770-2379
} 


\section{INTRODUÇÃO}

No atual contexto educacional é premente repensar estratégias que visem a superar defasagens educacionais e ampliem os horizontes que permeiam os processos de ensino. Para tanto, dentre as distintas estratégias evidencia-se a relevância de discutir e repensar sobre abordagens de temas transversais no espaço escolar. Nesse contexto, para Olgin e Groenwald (2015) os temas transversais, na atualidade, assumem a denominação de questões contemporâneas e/ou temas urgentes, porém sem perder a essência de serem assuntos relevantes que potencializem a formação do estudante.

Desta forma, dentre outros fatores contribuintes, este artigo objetiva investigar as representações conceituais sobre transversalidade de professores brasileiros, argentinos e uruguaios atuantes na região da tríplice fronteira destes países. O estudo embasa-se em autores que expressam a necessidade de averiguar, nos três países e dentro do setor do Mercado Comum da América do Sul (Mercosul), as concepções docentes sobre o tema, bem como os obstáculos em desenvolver práticas educativas em uma perspectiva transversal (SIEDE et al., 2015; AGUIRRE; ANDELIQUE, 2016). Para os autores, os povos fronteiriços partilham um modo de vida no qual é difícil dissociar as principais questões cotidianas dos países, sendo estas comuns a todos.

Nesta escrita considera-se como princípio conceitual que a transversalidade é uma prática educacional que estabelece uma relação entre estudar conhecimentos teoricamente sistematizados com temas que permeiam questões reais da vida dos educandos. A transversalidade tem por compromisso abordar, em uma perspectiva local, regional e global, aspectos e problemas emergentes da sociedade, discutir possíveis soluções e promover a conscientização do educando (ARAÚJO, 2014; LANES et al., 2015; HERRERA, 2016). Nesta perspectiva, o uso desta estratégia visa a romper com a visão dicotômica de separar conteúdos programáticos da realidade e do contexto do educando.

Vale destacar que orientações sobre abordagens transversais a partir de temas contemporâneos constam nos documentos educacionais dos países pesquisados, assim como em documentos do Mercosul Educacional, setor que coordena as políticas educacionais dos países associados ao Mercosul. No Brasil, os Parâmetros Curriculares Nacionais - Temas Transversais e a Base Nacional Comum Curricular; na Argentina, a Lei de Educação Nacional; no Uruguai, a Lei Geral de Educação; e, no Mercosul Educacional, nos Planos de Ação Educacional (VIÇOSA et al., 2020; D’ARCÁNGELO, 2016; DRI; SILVA, 2019). Para Siede et al. (2015), porém, somente as leis não garantem a efetivação e adoção desta estratégia; é preciso haver uma proposta eficaz de formação docente.

Sampaio e Côrtez (2020) reforçam o discurso de que é essencial discutir e investir em processos formativos para docentes em vista de desenvolver práticas pedagógicas que resultem em uma educação de qualidade condizente com a realidade. É basilar, segundo os autores, ofertar formações que promovam a articulação dos conhecimentos científicos com a prática do cotidiano. De fato, deve-se, por meio de políticas públicas, aspirar formações que considerem as questões atuais, com suas transformações e incertezas, e que direcionem para uma ação pedagógica fundamentada na realidade do educando. 
As formações, segundo Andreu-Andrés e Labrador-Piquer (2011), devem levar os professores a questionarem o porquê da desconexão da realidade com a prática da sala de aula. Deste modo, deve-se estimular a reflexão sobre quais mudanças são necessárias para melhorar as práticas de ensino. Este fato é válido, pois, apesar de algumas mudanças significativas no campo da educação, ainda encontramos situações que precisam ser ressignificadas em favor de um trabalho educativo de qualidade.

Desta forma, apesar da ciência de que existem distintas estratégias e abordagens metodológicas possíveis de serem utilizadas no processo de ensino aprendizagem, ressalta-se a transversalidade como uma forma de não estagnar este processo, sendo essencial, conforme afirmam Olgin e Groenwald (2015), pesquisar e discutir sobre o desenvolvimento de uma prática educativa que aporte as questões contemporâneas, que dê significado ao conhecimento produzido e que possibilite formar um estudante capaz de atuar na vida em sociedade. Assim, com base no exposto, este ensaio visa a identificar, entre docentes brasileiros, argentinos e uruguaios, as representações sobre transversalidade bem como os subsídios da formação continuada para o desenvolvimento de temas transversais.

\section{METODOLOGIA}

Trata-se de uma pesquisa qualitativa com propósito exploratório que segue os critérios estabelecidos por Gil (2008) sobre o objetivo, fidedignidade e validade dos dados coletados. Teve como cenário escolas públicas com baixo índice de desempenho situadas em regiões periféricas de cidades que fazem parte da tríplice fronteira dos países associados ao Mercosul: Brasil, Argentina e Uruguai. Ressalta-se que, como critério de exclusão, optou-se por não incluir o Paraguai, quarto país associado ao Mercosul, por este não fazer parte da tríplice fronteira formada pelos demais países integrantes do estudo. Participaram 30 professores de escolas públicas dos anos finais do Ensino Fundamental do Brasil, 54 docentes do III ciclo da Educação Geral Básica da Argentina e 12 professores do segundo ciclo da Educação Primária do Uruguai. O número diferenciado de professores uruguaios deve-se ao fato de esta escola caracterizar-se por possuir somente turno integral e por ser, dentre as três escolas da cidade, a que se enquadrava no perfil de cenário de inclusão da pesquisa.

Como instrumento de coleta de dados foi utilizado um questionário dividido em duas etapas. A primeira visou a traçar um perfil dos participantes com questões sobre gênero, Pós-Graduação, carga horária e tempo de docência. Na segunda etapa o objetivo foi identificar a representação conceitual dos professores sobre transversalidade, seus desdobramentos na prática docente e os subsídios da formação continuada sobre esta estratégia para o seu desenvolvimento na prática educativa.

Quadro 1-Questionário aplicado aos docentes

1) Qual sua concepção sobre transversalidade?

2) Você desenvolve propostas com temas transversais? Qual o tema mais trabalhado?

3) A formação continuada, da sua área de atuação contribui com desenvolvimento de temas transversais?

Fonte: Elaborado pelos autores. 
Os dados obtidos foram tratados e categorizados por meio da Análise de Conteúdo de Bardin (2011). Este método consiste em interpretar os dados de textos, questionários, entrevistas e outros documentos por meio da categorização, e objetiva atribuir uma compreensão aos significados expressos por meio do material analisado.

As categorias sobre as representações conceituais de transversalidade emergiram a partir da frequência descritiva e do tópico frasal de cada resposta dos participantes. A categorização considerou o conjunto total de respostas dos participantes, sem fragmentá-las por país, porém os extratos representativos das respostas foram renomeados de acordo com a nacionalidade de cada participante. Os temas transversais citados foram mostrados por intermédio de Nuvens de Palavras a partir da frequência descritiva, seguindo as orientações de Lemos (2016).

Acompanhando as normas e preceitos éticos legais, esta pesquisa foi aprovada pelo Comitê de Ética em Pesquisa (CEP) sob o Parecer número 1.746.820. Para garantir o anonimato dos participantes foi adotada a seguinte representação: PB (professores brasileiros), PA (professores argentinos) e PU (professores uruguaios).

\section{RESULTADOS E DISCUSSÃO}

\section{Caracterização dos participantes}

Dentre os 96 docentes argentinos, brasileiros e uruguaios participantes do estudo, 34,37\% possuem Pós-Graduação em distintas áreas do conhecimento. Os professores brasileiros apresentam um índice maior de Pós-Graduação e os professores argentinos expressam uma menor indicativa neste quesito. Em relação à carga horária, os docentes uruguaios apresentam um índice superior aos professores brasileiros e argentinos, superando as 40 horas semanais. Observa-se uma renovação no quadro docente do Brasil e Argentina, com $46,7 \%$ e $31,25 \%$ respectivamente com menos de dez anos de atuação. No Uruguai 6 docentes possuem entre 10 e 15 anos de atuação e outros 6 ultrapassam os 20 anos de docência.

O Quadro 2 apresenta o perfil detalhado dos participantes.

Quadro 2 - Perfil dos professores participantes

\begin{tabular}{|c|c|c|c|c|}
\hline País & Participantes & Pós-Graduação (\%) & $\begin{array}{l}\text { Carga Horária } \\
\text { Não Informou (NI) }\end{array}$ & $\begin{array}{l}\text { Tempo de Docência } \\
\text { Não Informou (NI) }\end{array}$ \\
\hline Brasil & 30 & $\begin{array}{l}\text { Sim: } 73,33 \% \\
\text { Não: } 26,67 \%\end{array}$ & $\begin{array}{c}20 \mathrm{~h}: 40 \% \\
\text { 40h: } 43,3 \% \\
>40 \mathrm{~h}: 16,7 \%\end{array}$ & $\begin{array}{c}<10 \text { anos }-46,7 \% \\
>10 \text { anos }-33,3 \% \\
>20 \text { anos }-20 \%\end{array}$ \\
\hline Argentina & 54 & $\begin{array}{l}\text { Sim: } 14,81 \% \\
\text { Não: } 85,19 \%\end{array}$ & $\begin{array}{c}\text { 20h: } 61,11 \% \\
>25 \mathrm{~h}: 16,67 \% \\
40 \mathrm{~h}-09,26 \% \\
\mathrm{NI}-12,96 \% \\
\end{array}$ & $\begin{array}{l}<10 \text { anos }-31,25 \% \\
>10 \text { anos }-37,50 \% \\
<20 \text { anos }-31,25 \%\end{array}$ \\
\hline Uruguai & 12 & $\begin{array}{l}\text { Sim: } 25 \% \\
\text { Não: } 75 \%\end{array}$ & $\begin{array}{l}\leq 20 \text { h } 16,67 \% \\
\geq 40 h 83,33 \%\end{array}$ & $\begin{aligned} & \geq 10: 50 \% \\
+ & 20 \text { anos: } 50 \%\end{aligned}$ \\
\hline
\end{tabular}

Fonte: Elaborado pelos autores. 


\section{Representações sobre transversalidade}

Ao se discutir a inserção de transversalidade no ensino é essencial traçar a compreensão docente sobre o assunto. Andreu-Andrés e Labrador-Piquer (2011) discorrem sobre a importância de identificar e considerar a compreensão docente sobre distintos temas para, posteriormente, delinear metas formativas. Nesta perspectiva os dados analisados e tratados resultaram nas categorias a seguir apresentadas a partir das representações conceituais expressas nas respostas.

Gráfico 1 - Categorias resultantes da representação conceitual sobre transversalidade (\%)

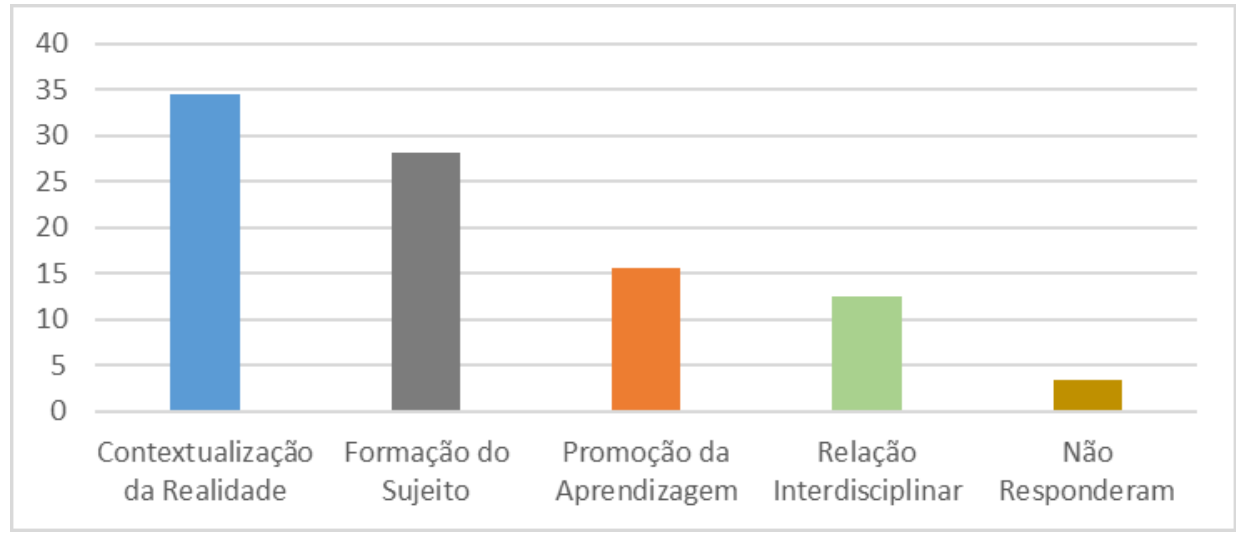

Fonte: Elaborado pelos autores.

O total das respostas válidas resultou em quatro categorias, posto que $9,4 \%$ dos participantes não responderam. A transversalidade, para 34,3\%, refere-se à Contextualização da Realidade, para $28,1 \%$ à Formação do Sujeito, para 15,6\% à Promoção da Aprendizagem e para $12,6 \%$ à Relação Interdisciplinar. Estas categorias emergiram a partir da frequência descritiva e do principal tópico frasal de cada resposta. No Quadro 3 apresentamos a descrição resultante de cada categoria.

Quadro 3 - Descrição das Categorias

\begin{tabular}{|l|l|}
\hline \multicolumn{1}{|c|}{ Categoria } & \multicolumn{1}{|c|}{ Descrição } \\
\hline $\begin{array}{l}\text { Contextualização da } \\
\text { Realidade }\end{array}$ & $\begin{array}{l}\text { Abordar e problematizar temas da realidade do educando } \\
\text { relacionando com os conteúdos programáticos do currículo. }\end{array}$ \\
\hline Formação do Sujeito & $\begin{array}{l}\text { Desenvolver questões da vida real na perspectiva de auxiliar } \\
\text { na formação do educando como cidadão crítico e atuante na } \\
\text { sociedade. }\end{array}$ \\
\hline $\begin{array}{l}\text { Promoção da } \\
\text { Aprendizagem }\end{array}$ & $\begin{array}{l}\text { Promover a aprendizagem significativa a partir da relação da teoria } \\
\text { com temas do contexto do educando. }\end{array}$ \\
\hline Relação Interdisciplinar & $\begin{array}{l}\text { Articular temas e conteúdos entre distintas disciplinas, sem } \\
\text { fragmentar o conhecimento. }\end{array}$ \\
\hline
\end{tabular}

Fonte: Elaborado pelos autores.

A correlação das categorias indica que a representação conceitual dos professores sobre transversalidade contempla o contexto do educando em uma perspectiva de promover a aprendizagem e de formar sujeitos atuantes no meio em que estão inseridos. Os docentes compreendem que a transversalidade no ensino visa a aproximar assuntos da realidade dos estudantes às disciplinas curriculares tradicionais, expandindo a com- 
preensão e a criticidade sobre distintas informações. Desse modo, a transversalidade inclina, por essência, a se contrapor à lógica segmentada e restrita do currículo e objetiva uma nova organização de conhecimentos.

\section{i. Contextualização da Realidade}

A categoria Contextualização da Realidade emergiu como resposta para 34,3\% dos docentes. Nesta categoria compreende-se que a transversalidade versa sobre abordar e problematizar temas da realidade do educando relacionando-os com os conteúdos programáticos do currículo. Contextualiza-se na perspectiva de facultar a interpretação e a compreensão de conteúdos articulados ao cotidiano dos educandos, de modo a resultar em uma visão crítica do mundo natural e social.

Ressalta-se, porém, que este termo não deve ser utilizado como um pano de fundo para encobrir a abstração excessiva de um ensino puramente conceitual. A contextualização, segundo Chassot (2018), não deve se assemelhar à mera exemplificação ou simples sistematização dos conhecimentos advindos do senso comum, perdendo o sentido da aprendizagem dos conteúdos escolares. Nesta perspectiva, a contextualização configura-se, conforme o recorte das respostas a seguir apresentado, como propulsora na problematização de temas do cotidiano e como uma metodologia capaz de dinamizar os processos de construção de significados.

$\mathrm{PB}_{17}: \mathrm{A}$ transversalidade está ligada aos conteúdos que envolvam o contexto dos alunos, temas que não são os conteúdos propriamente ditos da grade curricular e sim temas anexos da realidade escolar.

$\mathrm{PA}_{19}$ : É uma estratégia pedagógica educativa que articula, engenha e contextualiza conteúdos com as capacidades intelectuais, éticas, afetivas, sociais, conectando a escola com questões cotidiana dos alunos.

$\mathrm{PU}_{12}$ : São assuntos que devemos inserir em sala de aula de maneira contextualizada ao conteúdo do currículo, atual e de interesse dos alunos e que faça parte da realidade deles e que promova uma conexão entre saberes científicos e do cotidiano.

De acordo com Veloso e Dal-Farra (2015), é mister a contextualização dos conteúdos com as questões sociais atuais que permeiam a prática educativa, tais como ética, meio ambiente, saúde, sexualidade, trabalho, consumo, entre outros. O viés da abordagem transversal contextualizada "se torna um campo do conhecimento de muita importância para fomentar soluções às demandas atuais da sociedade" (VELOSO; DAL-FARRA, 2015 , p. 5). Este fato desafia paradigmas educacionais e contribui na concepção docente de que esta estratégia serve para derrubar barreiras, que dificultam a formação de indivíduos críticos e autônomos, e auxiliar na promoção da aprendizagem.

A contextualização da realidade com o currículo escolar é tratada pela literatura dos países que fazem parte desta pesquisa. Autores argentinos, brasileiros e uruguaios destacam a necessidade de que os contextos histórico, cultural e social dos educandos façam parte efetivamente do desenho curricular dos países, dando suporte básico para a aprendizagem dos educandos (D’ARCÁNGELO, 2016; CALDEIRA; GONÇALVEZ, 2016; OROÑO, 2014). Desta forma, o ensino contextualizado é visto como uma estratégia ancorada na problematização de situações reais e propulsionadora da desconstrução e reconstrução de conceitos básicos pelo educando. 
Conforme Chassot (2018), é urgente a ressignificação do ensino por intermédio da contextualização de conteúdos com temas do cotidiano do educando. Para o autor, o ensino contextualizado deve caracterizar-se como um instrumento da leitura da realidade e facilitador para o desenvolvimento de uma visão crítica do mundo. Nesta lógica, entende-se que a contextualização da realidade, conforme explicitado pelo grupo de participantes, auxilia na resolução dos conflitos emergentes entre saberes oriundos de diferentes âmbitos, científicos e do senso comum, no processo de ensino e aprendizagem.

\section{ii. Formação do Sujeito}

A compreensão de que a transversalidade está interligada à Formação do Sujeito foi citada por $28,1 \%$ dos participantes. A transversalidade, para os professores desta categoria, condiz em desenvolver questões da vida real na perspectiva de auxiliar na formação do educando como cidadão crítico e atuante na sociedade. Para Freire (2000), a formação do sujeito se dá por meio de uma educação que constitua o educando em agente político, consciente de sua identidade, de seu tempo, de sua história e da sua cultura no contexto global. A seguir um extrato da representação de transversalidade desta categoria.

PB14: Aprender na prática educativa ou na vida real conceitos de uma realidade, buscando vários temas geradores reais estabelecendo os mesmos na prática educativa para formar educandos críticos e participativos na sociedade.

PA50: Refere-se a assuntos que ajudam a formar um aluno consciente, que devem ir além dos conteúdos e auxiliar na construção de uma visão crítica, política e cultural da sociedade em que vive.

PU03: São temas que não estão no programa escolar, mas que afetam a todos e são muito importantes na formação integral do aluno para a construção de um olhar crítico do mundo, considerando a cultura e política da sua e de outras sociedades.

As prospecções dos docentes sinalizam para um ensino em que a transversalidade considere uma relação entre sujeito e objeto de estudo. De acordo com Caldeira e Gonçalvez (2016), a escola constitui-se como uma agência de fomento dos princípios que sustentam o desenvolvimento do indivíduo, bem como sua inserção nas diversas realidades sociais. Desta forma, potencializa a capacidade do educando em participar efetivamente da vida em comunidade a partir de uma formação emancipadora que considere questões urgentes de seu contexto.

Para Freire (2000), a educação, na ótica formativa de um sujeito crítico, deve ser mediada pelo professor nos permanentes processos de relação dialógica com o educando, para, juntos, atuarem, desvelarem e recriarem a realidade. Nesta perspectiva, D'Arcángelo (2016) sinaliza a necessidade de delinear respostas à crescente complexidade e importância que o cotidiano escolar assumiu na formação do educando. Este tipo de delineamento deve ter como prisma a formação do sujeito em uma ótica política, sem ser partidária, que auxilie o educando a compreender as distintas transformações educacionais, socioculturais e socioeconômicas do mundo.

Ao ter por desígnio a formação integral do sujeito, deve-se possuir por princípio a inclusão de temas urgentes tanto à sociedade quanto aos educandos. Estes temas "são conteúdos transversais que incluem demandas sociais, ambientais, comunitárias ou tra- 
balhistas e problemas relacionados a tópicos, procedimentos ou atitudes de interesse geral" (SIEDE et al., 2015, p. 53). Nesta dimensão, o indivíduo em processo de formação tende a desenvolver um grau de autonomia e de criticidade que o possibilitará analisar e refletir para além de seu contexto e dos conteúdos curriculares ofertados em modelos normativos educacionais.

\section{iii. Promoção da Aprendizagem}

A terceira categoria, Promoção da Aprendizagem, citada por 15,6\% dos participantes, concebe que a transversalidade favorece a construção de saberes significativos dos educandos a partir da relação da teoria com temas do contexto. Conforme Ausubel (1982), aprender significativamente é ampliar e reconfigurar ideias já existentes na estrutura mental, e, com isso, ser capaz de relacionar e acessar novos conteúdos. Nesse contexto, é possível relacionar a nova informação de maneira substancial com algum aspecto da estrutura cognitiva prévia que lhe for relevante e atribua novos significados aos conteúdos desenvolvidos.

Para Araújo (2014), a transversalidade coopera com o processo de aprendizagem a partir da troca constante, entre professor e alunos, de saberes e informações que abrem caminho para novas construções de saberes. Os autores ressaltam, porém, que dentro da dimensão pedagógica os temas transversais não devem resumir-se à explanação de conceitos técnicos, pois isso limita o acesso aos conhecimentos prévios dos educandos. Tal limitação poderia ceifar a possibilidade de sintetizar outras formas de informação e promover a aprendizagem significativa. A seguir apresenta-se fragmentos das respostas que se destacaram nesta categoria.

PB7: É trabalhar em sala de aula a partir da vivência do aluno(a), aliando a teoria com a prática de forma que resulte em uma real aprendizagem do aluno.

PA14: Busca olhar a experiência escolar como uma oportunidade para que as aprendizagens integrem diferentes dimensões cognitivas e formativas, não estando relacionada somente ao currículo, mas na aprendizagem significativa dos estudantes

PU04: É a necessidade de trabalhar conceitos que não estão dentro do conteúdo curricular, mas que possam ajudar na aprendizagem significativa do aluno.

A partir destes extratos pode-se entender que a transversalidade, na visão dos participantes, é um fator propulsor para a aprendizagem significativa. Assim, diferentemente da categoria anterior, que compreende a transversalidade como propulsora da formação de um sujeito crítico, reflexivo e atuante na sociedade, esta categoria a compreende como promotora de sentidos e significados dos saberes prévios do educando. Para Gomes e Garcia (2014), o ato de ensinar deve atribuir significados a conceitos com vistas a uma melhor compreensão da realidade e considerar fatores reais do público escolar.

A representação docente, elencada nesta categoria, vai ao encontro do abordado por Lanes et al. (2015) sobre utilizar a realidade como elemento gerador e contextualizador do conhecimento ensinado e aprendido em sala de aula. Para os autores, a falta de significados faz com que exista um menor engajamento do educando no processo de 
aprendizagem. De fato, a falta de relação entre conteúdo e os saberes prévios, resultantes do contexto dos educandos, configura-se como um fator limitante na construção da aprendizagem.

Nesta perspectiva, a aprendizagem significativa pode ser estruturada a partir de situações e questões que façam parte do seu cotidiano. Para Gomes e Garcia (2014), a utilização de atividades didáticas, com estratégias metodológicas diversificadas, facilita a aprendizagem dos estudantes, favorecendo a evolução e a significação conceitual. Dentro desse contexto, é viável a inserção de temas de interesse específicos às realidades escolares heterogêneas, de modo a contribuir com o processo de aprendizagem dos educandos.

\section{iv. Relação Interdisciplinar}

Nesta categoria a transversalidade é relacionada por $12,6 \%$ dos participantes ao conceito de interdisciplinaridade. Para estes docentes a transversalidade tem por princípio propiciar a articulação de temas e conteúdos entre distintas disciplinas e superar a fragmentação de saberes. De acordo com Araújo (2014), este equívoco na interpretação dos conceitos relaciona-se a uma formação deficitária que não contempla adequadamente estas potencialidades educacionais. Segue um extrato das respostas desta categoria.

$\mathrm{PB}_{25}$ : São temas que podem ser articulados com várias disciplinas de forma interdisciplinar no sentido de evitar a fragmentação.

$\mathrm{PA}_{29}$ : São conteúdos que devem ser desenvolvidos integrados em todas as disciplinas que contribuam para o desenvolvimento do aluno e não sejam fragmentados.

$\mathrm{PU}_{09}$ : São linhas de discussão importantes que devem ser trabalhadas paralelamente aos conteúdos e articuladas com outras disciplinas.

O discurso apresentado por essa categoria coincide com a concepção de alguns autores sobre interdisciplinaridade. Para Fazenda (2012), a interdisciplinaridade refere-se a uma relação-articulação que questiona e se propõe a superar a segmentação entre os diferentes campos de conhecimento, enquanto a transversalidade, conforme a autora, é condizente a promover conceitos, atitudes e procedimentos por meio de temas da realidade.

Os termos transversalidade e interdisciplinaridade, apesar de distintos conceitos e objetivos, na prática pedagógica complementam-se e se nutrem mutuamente em prol do desenvolvimento do educando (ARAÚJO, 2014). Conforme o autor, as questões transversais devem ser conduzidas por meio de um viés interdisciplinar, haja vista não terem sentido sem uma abordagem histórica, econômica ou sociológica. A diferenciação terminológica, porém, é essencial na perspectiva de superar um modelo de ensino segmentado e para a inserção de propostas transversais nas práticas educativas.

A compreensão conceitual, tanto de transversalidade quanto de interdisciplinaridade, de acordo com Araújo (2014), é cogente na organização de propostas pedagógicas. De fato, a compreensão destes conceitos constitui-se em necessidade na con- 
temporaneidade, sobretudo quando, segundo Veloso e Dal-Farra (2015), se busca a formação de docentes capacitados a construir ações efetivas e calcadas em princípios educacionais relevantes.

Investigações educacionais dos países integrantes da pesquisa têm mostrado a pertinência da diferenciação conceitual destes termos. O docente deve compreender que a transversalidade versa sobre questões relativas a valores e atitudes que permeiam o contexto da sociedade, e que a interdisciplinaridade articula e integra essas questões em todas as disciplinas (HERRERA, 2016; D’ARCÁNGELO, 2016; ARAúJO, 2014). Assim, é preciso reconhecer a distinção entre as terminologias, pois as duas, mesmo distintas, possuem protagonismo no processo de ensino e aprendizagem e são fundamentais na ressignificação do trabalho pedagógico e docente.

\section{A transversalidade como prática educativa}

A escola, por excelência, é um dos ambientes sociais formadores de princípios importantes para o desenvolvimento do educando. Para Bikoski, Ladelfo e Schmitz (2016), por ser um ambiente sustentado pela diversidade, a escola torna-se uma referência de espaço social e promotora de discussões de interesse urgente aos educandos. Neste viés, os participantes foram questionados sobre o desenvolvimento de propostas transversais em sua prática educativa.

Os resultados indicaram que $36,5 \%$ dos docentes realizam este tipo de abordagem regularmente, 40,6\% afirmaram trabalhar eventualmente com algum tipo de tema e $22,9 \%$ não realizam abordagens transversais. A vista destes dados, observa-se que a transversalidade não faz parte da prática educativa diária da maioria dos docentes brasileiros, argentinos e uruguaios participantes deste estudo. Para Sampaio e Côrtes (2020), é pertinente buscar essas informações, pois é notório que a transversalidade, como estratégia educacional, permite a expansão da compreensão e da criticidade sobre distintas informações pelo educando.

Deste modo, os docentes foram questionados sobre quais temas abordam em sala de aula. Os dados obtidos foram organizados por meio de Nuvem de Palavras, e as palavras em destaque indicam a frequência com que constaram nas respostas.

Figura 1 - Descritores docentes brasileiros

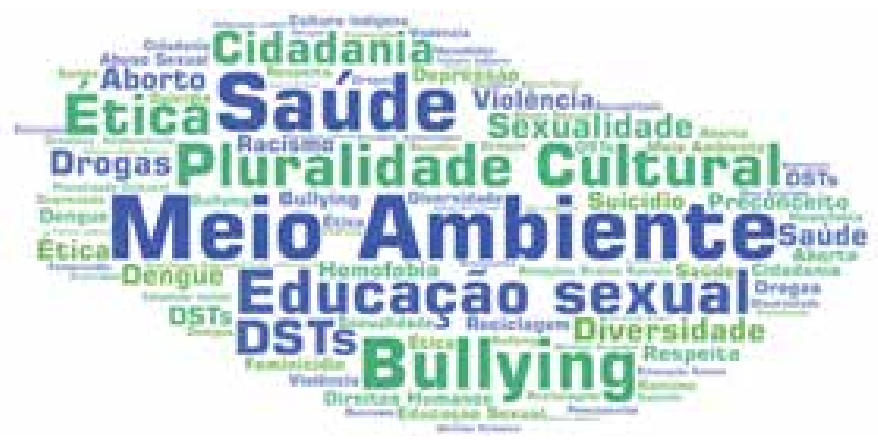

Fonte: Elaborada pelos autores. 
Figura 2 - Descritores docentes argentinos

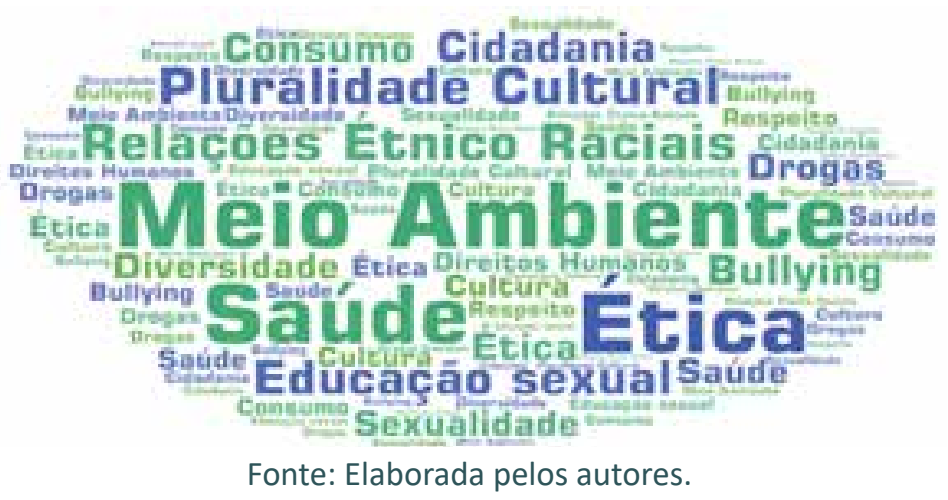

Figura 3 - Descritores docentes uruguaios

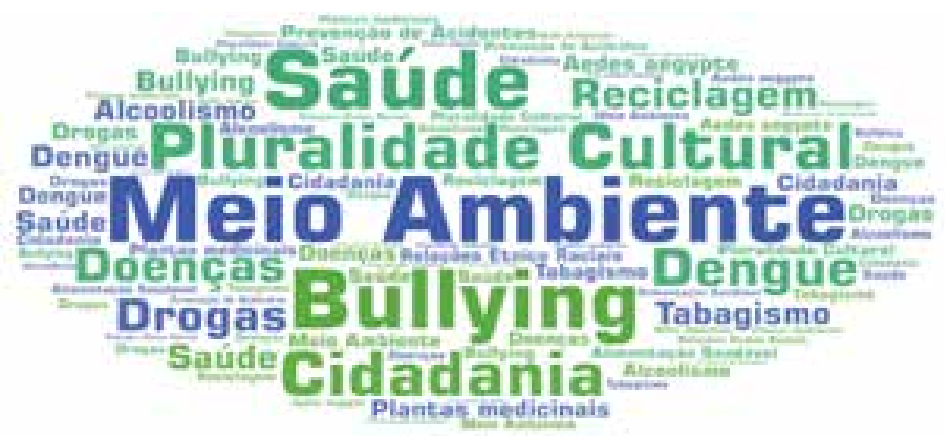

Fonte: Elaborada pelos autores.

Como resultado, pode-se identificar que o descritor Meio Ambiente apresentou maior frequência nas respostas, com questões relacionadas à reciclagem, à preservação ambiental e ao Aedes Aegypti. Na sequência, o tema Saúde, apesar do destaque, também foi descrito de forma fracionada por distintos termos, como doenças, dengue, medicamentos, alimentação saudável, chás medicinais, drogas, depressão, alcoolismo e suicídio. Pluralidade Cultural, Relações Étnico Raciais e Ética apresentam-se como descritores em destaque com temas envolvendo a cultura indígena, diversidade, preconceito, bullying, cidadania e respeito.

Temas conexos à Educação Sexual, como gravidez, aborto, abuso sexual, sexualidade, feminicídio e homofobia, são citados, porém os descritores não emergem com frequência significativa. De forma semelhante, as questões relacionadas à violência, consumo e prevenção de acidentes, aparecem com menor frequência. De acordo com Tardif e Lessard (2005), deve-se averiguar a dificuldade docente em trabalhar estes tipos de questões, pois são representativas de temas urgentes aos educandos e que devem fazer parte das discussões no contexto escolar.

Vale ressaltar que, segundo Viçosa et al. (2020), as leis educacionais da Argentina e Uruguai, diferentemente do Brasil, direcionam para a abordagem da Educação Sexual nas práticas educativas de todos os componentes curriculares, além de destacarem ser essencial uma formação que prepare o docente a trabalhar distintas questões em sala de aula. Para Tardif e Lessard (2005), é preciso investir nas políticas públicas de formação, pois os professores ocupam uma posição fundamental como mediadores na construção do conhecimento do educando. 
Nesse sentido, concordamos com Sampaio e Côrtes (2020), que inferem a necessidade da melhoria em diversos aspectos relacionados à educação, dentre esses os progressos que envolvam a formação integral do discente. O conjunto de aprendizados que circunda os enfoques transversais, para Bikoski, Ladelfo e Schmitz (2016), tende a alavancar positivamente o processo educacional. De fato, a convivência em um ambiente diversificado, permeado por discussões e problematizações de questões urgentes, é um fator impulsionador na reinvenção e na ressignificação de saberes dos educandos.

\section{Subsídios da formação continuada para o enfoque transversal}

Um dos fundamentos da formação continuada diz respeito, segundo Sampaio e Côrtez (2020), à ampliação do horizonte docente, ressaltando os saberes específicos da profissão bem como o conhecimento sobre as atualidades que condicionam a sociedade. Neste sentido, os docentes foram consultados sobre a contribuição da formação continuada no desenvolvimento de questões transversais em sua área de atuação. Os resultados deste questionamento são apresentados no Gráfico 2.

Gráfico 2 - A formação continuada contribui com o desenvolvimento de temas transversais? (\%)

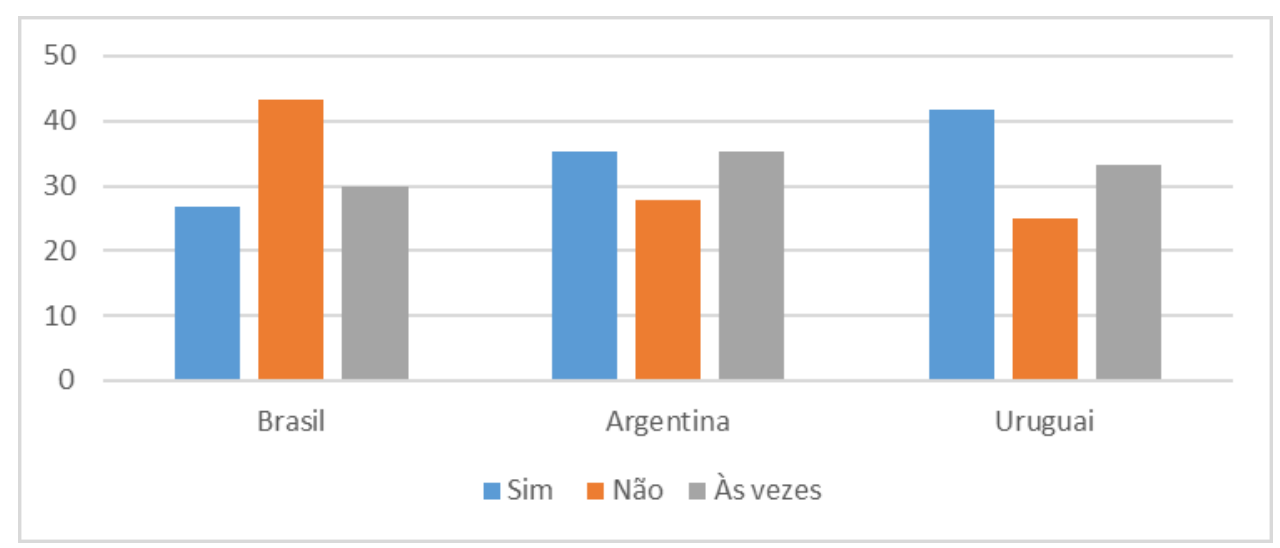

Fonte: Elaborado pelos autores.

A partir do Gráfico observa-se que $41,7 \%$ dos docentes uruguaios, $35,2 \%$ dos docentes argentinos e $26,7 \%$ dos participantes brasileiros compreendem que a formação contempla este quesito. A não existência de subsídios foi resposta de $43,3 \%$ dos docentes brasileiros, seguido por $27,8 \%$ e $25 \%$ respostas de docentes argentinos e docentes uruguaios, respectivamente. A ocorrência eventual em formações sobre questões transversais ocorre para $37 \%$ de participantes argentinos, $33,3 \%$ de docentes uruguaios e $30 \%$ dos docentes brasileiros.

Este dado demonstra que o Uruguai, além de garantir em lei a abordagem de eixos transversais, possui políticas públicas de formação docente que buscam atender essa demanda. De fato, segundo Dri e Silva (2019), o Uruguai destaca-se em relação à Argentina e ao Brasil quando o assunto é formação de professores. Para as autoras, este protagonismo deve-se ao movimento de fortalecimento do Conselho de Formação em Educação do país por meio de distintos setores de organizações formativas educacionais.

Este fortalecimento pode ter sido um fator que contribuiu para que o Uruguai tenha se destacado, em relação aos demais países analisados, no ranking organizado pelo Programme for International Student Assessment (Pisa) no ano de 2018, conforme in- 
formações da Organização para a Cooperação e Desenvolvimento Econômico (OCDE, 2019). Dados do Instituto Nacional de Estudos e Pesquisa Educacionais Anísio Teixeira (Inep) (BRASIL, 2019) sobre o Pisa/2018, indicam que o Uruguai se destaca do Brasil e da Argentina nas três áreas: Leitura, Matemática e Ciências. Brasil e Argentina são considerados tecnicamente empatados por apresentarem pontuação com pequena margem de diferença em todas as áreas avaliadas, o que reforça ser primordial investir em formação docente de qualidade.

Alliaud e Vezub (2014), ao analisarem a formação continuada de professores no Mercosul, ressaltam que o acréscimo de estratégias que contemplem temas do contexto educacional nos países integrantes desta pesquisa ocorre de forma gradual. De acordo com as autoras, estes países, assim como os demais associados do Mercosul, adotam uma linha mecanicista em formato de palestras nas formações, sem considerar as reais necessidades expressas pelos docentes. À vista disso, entende-se ser premente instituir propostas formativas para além do modelo adotado, de modo que o docente exerça o papel de protagonismo e possa expor seus anseios dentro da prática educativa.

Vásquez e Alsina (2014), em estudos na América do Sul com a perspectiva de identificar os obstáculos de formação docente, consideram ser mister adaptar ou reestruturar os atuais programas de formação continuada de professores. Para os autores, muitos professores limitam-se a ensinar um conjunto de conteúdos sem maiores interpretações, o que dificulta a construção de conhecimento dos educandos. De acordo com Dri e Silva (2019), a tendência de reformulações na América do Sul deveria seguir a linha do contexto europeu, quando a qualidade educacional perpassa pela qualificação docente, salários e planos de carreiras profícuos.

Para Thiollent e Colette (2014), é essencial a regulamentação em legislação dos processos formativos docentes e o planejamento desses em sintonia com a diversidade das situações que emergem na sociedade. Atentos a esta questão, os autores observam que a formação continuada, se distanciada da ideia de reciclagem, legitima, reafirma e dá autenticidade à uma formação que se contextualiza embasada na prática docente. De fato, a formação é um fator que permite ao docente aperfeiçoar as suas práticas pedagógicas e gerar transformação e impacto no contexto escolar.

$\mathrm{Na}$ literatura dos países pesquisados consta estudos que apontam ser primordial que ocorra uma modificação nos processos formativos. Uma proposta atual de formação docente deve considerar demandas sociais, políticas culturais, comunitárias e procedimentos ou atitudes de interesse geral da sociedade de maneira que auxiliem o professor na sua prática diária (SIEDE et al., 2015; VÁSQUEZ; ALSINA, 2014; THIOLLENT; COLETTE, 2014). Nesta perspectiva, o desafio da formação continuada está em ser pautada em pilares colaborativos, dialógicos e participativos, que potencializem, desvelem e superem uma prática fragmentada e distante das questões presentes no contexto do educando.

A formação continuada docente, conforme Thiollent e Colette (2014), deve ser concebida como reflexão, pesquisa, ação e organizada com a inserção de fatores do cotidiano do educando. Segundo os autores, porém, nas formações é predominante o caráter clássico, pois são realizadas mediante oferta de modalidades tradicionais, como palestras e cursos em que o docente tem o papel de ouvinte. De fato, observam-se, no 
âmbito educacional dos três países, lacunas referentes a iniciativas concretas de formação continuada que forneçam aporte para abordagens efetivas de questões transversais na escola.

\section{CONSIDERAÇÕES FINAIS}

Ao final deste estudo entende-se ser primordial a ratificação e a ampliação do uso da transversalidade como estratégia em processos educacionais dos países integrantes do estudo. As representações sobre transversalidade direcionam para a transformação dos conceitos, a explicitação de valores e a inclusão de procedimentos vinculados ao cotidiano do educando, exigindo ações que ampliem os significados elaborados na construção do conhecimento. Reconhece-se a interdependência das questões contemporâneas que compõem a realidade das escolas fronteiriças e que o cognoscível desse todo implica uma articulação entre os saberes científicos e os construídos a partir da realidade de cada país.

Depreende-se que, apesar das peculiaridades educacionais de cada país, os docentes buscam nas questões transversais uma possibilidade de contribuir no processo de aprendizagem e na formação dos educandos. Ressalta-se que, apesar de o Uruguai se destacar em relação aos demais países quanto ao processo formativo, os subsídios da formação continuada sobre esta estratégia ainda são limitados nos três países. Assim, é basilar a construção de ambientes formativos, institucionais e pedagógicos que integrem questões transversais a saberes constantes nos currículos destes países.

Entende-se, todavia, que a introdução de um modelo de formação, que abarque questões urgentes à sociedade, colide em contingências presentes nos sistemas de ensino e na ausência de políticas formativas. Diante do cenário contemporâneo, porém, é primordial superar estas adversidades e promover ações de enfrentamento pedagógico de teorias e propostas distanciadas da realidade que já estão impregnadas na prática docente. Deste modo, compreende-se ser incipiente a inserção da transversalidade nas práticas educativas e nas formações continuadas da área fronteiriça, visando a superar paradigmas tradicionais de ensino e aproximar, de forma individual e coletiva, os segmentos educacionais destes países.

\section{REFERÊNCIAS}

AGUIRRE, M. C.; ANDELIQUE, C. La enseñanza de la ciudadanía a partir de contenidos curriculares comunes. Revista de Educación, v. 7, n. 9, 2016. Disponível em: https://fh.mdp.edu.ar/revistas/index.php/r_ educ/article/view/1912. Acesso em: 4 jul. 2020.

ALLIAUD, A.; VEZUB, S. La formación docente en el nivel superior de Argentina: hacia la conformación de un sistema integrado. Revista Latinoamericana de Políticas y Administración de la Educación, v. 1, n. 1, 2014. Disponível em: http://relapae.untref.edu.ar/numero-1/. Acesso em: 2 jul. 2020.

ANDREU-ANDRÉS, M. Á.; LABRADOR-PIQUER, M. J. Formación del profesorado en metodologías y evaluación. Análisis cualitativo. Revista de Investigación en Educación, v. 9, n. 2, 2011. Disponível em: https:// dialnet.unirioja.es/servlet/articulo?codigo=4731787. Acesso em: 4 jul. 2020.

ARAÚJO, U. F. Temas transversais, pedagogia de projetos e as mudanças na educação. São Paulo: Summus, 2014.

AUSUBEL, D. P. A aprendizagem significativa: a teoria de David Ausubel. São Paulo: Moraes, 1982.

BARDIN, L. Análise de conteúdo. 3. ed. Lisboa: Edições 70, 2011. 
BIKOSKI, G. F.; LADELFO, J.; SCHMITZ, P. D. Diálogos e reflexões éticas sobre DSTs, sexo, sexualidade e gênero no ensino médio: uma oficina didática calcada em temas transversais. Scientia Tec, v. 3, n. 2, 2016. Disponível em: https://periodicos.ffrs.edu.br/index.php/ScientiaTec/article/view/1597. Acesso em: 9 jul. 2020.

BRASIL. Instituto Nacional de Estudos e Pesquisa Educacionais Anísio Teixeira. Relatório Programa Internacional de Avaliação de Alunos/2018. 2019. Disponível em: http://portal.inep.gov.br/web/guest/acoes-internacionais/pisa/resultados. Acesso em: 22 jul. 2020.

CALDEIRA, D. L.; GONÇALVEZ, D. S. Discussões sobre trabalho com suporte em crônicas brasileiras sobre trabalhadores: temas transversais em um contexto de letramento digital. In: FARIA, A. A. M. de; GONÇALVES, D. dos S.; SOARES, M. J. H. Linguagem, Trabalho, Educação e Cultura. Belo Horizonte: Fale/UFMG, 2016. p. 70-88.

CHASSOT, A. Alfabetização científica: questões e desafios para a educação. ljuí: Editora Unijuí, 2018.

DRI, W. I. O.; SILVA, L. L. Formação continuada de professores e regionalização educativa: uma análise das políticas do setor educacional do MERCOSUL. Acta Scientiarum, v. 41, n. 1, 2019. Disponível em: http:// periodicos.uem.br/ojs/index.php/ActaSciEduc/article/view/44930. Acesso em: 11 ago. 2020.

D'ARCÁNGELO, M. B. Reconfiguraciones en el cambio de siglo: educar en y para la democracia. Nuevos sentidos de la formación ciudadana. Espacios en Blanco: Revista de Educación, v. 26, 2016. Disponível em: https://www.redalyc.org/articulo.oa?id=3845/384547076014. Acesso em: 13 jul. 2020.

FAZENDA, I. C. A. Interdisciplinaridade: história, teoria e pesquisa. 18. ed. Campinas, SP: Papirus, 2012.

FREIRE, P. Pedagogia da indignação: cartas pedagógicas e outros escritos. São Paulo: Unesp, 2000.

GIL, A. C. Métodos e técnicas de pesquisa social. 6. ed. São Paulo: Atlas, 2008.

GOMES, A. T.; GARCIA, I. K. Aprendizagem significativa na EJA: uma análise da evolução conceitual a partir de uma intervenção didática com a temática energia. Investigaçães no Ensino de Ciências, v. 19, n. 2, 2014. Disponível em: https://www.if.ufrgs.br/cref/ojs/index.php/ienci/article/view/81/56. Acesso em: 3 jul. 2020.

HERRERA, M. A. P. Currículo Transversal en la Contemporaneidad. Escenarios, v. 14, n. 1, 2016. Disponível em: http://ojs.uac.edu.co/index.php/escenarios/article/view/881. Acesso em: 14 jul. 2020.

LANES, K.; CECCON, D.; PESSANO, E. F; FOLMER. V. O ensino de ciências e os temas transversais: práticas pedagógicas no contexto escolar. Revista Contexto \& Educação, v. 29, n. 92, 2015. Disponível em: https:// www.revistas.unijui.edu.br/index.php/contextoeducacao/article/view/2371. Acesso em: 16 ago. 2020.

LEMOS, L. M. P. Nuvem de tags como ferramenta de análise de conteúdo: uma experiência com as cenas estendidas. Lumina, v. 10, n. 1, 2016. Disponível em: https://periodicos.ufjf.br/index.php/lumina/article/ view/21192. Acesso em: 4 jul. 2020.

OLGIN, C. A.; GROENWALD, C. L. O. Critérios para seleção de temas de interesse para o Currículo de Matemática do Ensino Médio. Perspectivas da Educação Matemática, v. 8, n. 17, 2015. Disponível em: https:// periodicos.ufms.br/index.php/pedmat/article/view/988. Acesso em: ago. 2020.

OCDE. Organização para Cooperação e Desenvolvimento Econômico. Programme for International Student Assessment (PISA)/2018. 2019. Disponivel em: https://www.oecd.org/pisa/publications/pisa-2018-results.htm. Acesso em: ago. 2020.

OROÑO, M. La escuela y la lengua en la construcción de la identidad nacional uruguaya: los libros de lectura usados en la escuela pública en los años 40 del siglo XX. Boletín de Filología, v. 49, n. 2, 2014. Disponível em: https://boletinfilologia.uchile.cl/index.php/BDF/article/view/35860. Acesso em: jul. 2020. SAMPAIO, J. C.; CÔRTEZ, E. G. Análise do livro didático sob a perspectiva dos temas transversais e da estatística. Scientia, v. 5, n. 2, 2020. Disponível em: https://www.revistas.uneb.br/index.php/scientia/article/ view/8181. Acesso em: 16 jul. 2020.

SIEDE, I. A.; GUGLIELMINO, E.; ALCAIN, J.; FERNÁNDEZ, G.; GUINAO, D. Formação ética e cidadania. Vicissitudes da transformação curricular na Patagônia Argentina. Folios, v. 41, 2015. Disponível em: https:// revistas.pedagogica.edu.co/index.php/RF/article/view/2945. Acesso em: 23 jul. 2020.

TARDIF, M.; LESSARD, C. $O$ trabalho docente: elementos para uma teoria da docência como profissão de interações humanas. Petrópolis: Vozes, 2005.

THIOLLENT, M. J. M.; COLETTE, M. M. Pesquisa-ação, formação de professores e diversidade. Acta Scientiarum. Human and Social Sciences, v. 36, n. 2, 2014. Disponível em: http://periodicos.uem.br/ojs/index. php/ActaSciHumanSocSci/article/view/23626. Acesso em: 24 jul. 2020.

VÁSQUEZ, C.; ALSINA, Á. Enseñanza de la Probabilidad en Educación Primaria. Un Desafío para la Formación Inicial y Continua del Profesorado. Revista de Didáctica de las Matemáticas, v. 85, 2014. Disponível em: https://dialnet.unirioja.es/servlet/articulo?codigo=4611701. Acesso em: 4 ago. 2020. 
VELOSO, N. D.; DAL-FARRA, R. A. Educação ambiental na formação inicial de professores de matemática em Boa Vista/RR: temas transversais e interdisciplinaridade. Tear: Revista de Educação Ciência e Tecnologia, v. 4, n. 2, 2015. Disponível em: https://doi.org/10.35819/tear.v4.n2.a1935. Acesso em: 5 ago. 2020.

VIÇOSA, C. S. C. L.; SANTANA, E. B.; VIÇOSA, D. L.; LIMA, Q. C. E.; D’ANDREA, A. M.; SALGUEIRO, A. C. F.; FOLMER, V. Adolescent health and sex education at school: weavings from students' perspectives. $R e-$ search, Society and Development, v. 9, n. 6, 2020. Disponível em: https://rsdjournal.org/index.php/rsd/ article/view/3613. Acesso em: 13 ago. 2020. 